\title{
Clinical examination and classification systems of congenital clubfoot: a narrative review
}

\author{
Federico Canavese $^{1,2} \wedge$, Alain Dimeglio ${ }^{3 \wedge}$ \\ ${ }^{1}$ Department of Pediatric Orthopedic Surgery, Lille University Center, Jeanne de Flandre Hospital, Lille, France; ${ }^{2}$ Nord-de-France University, \\ Faculty of Medicine Henri Warembourg, Lille, France; ${ }^{3}$ University of Montpellier, Faculty of Medicine, 2 Rue de l'École de Médecine, Montpellier, \\ France \\ Contributions: (I) Conception and design: Both authors; (II) Administrative support: Both authors; (III) Provision of study materials or patients: \\ Both authors; (IV) Collection and assembly of data: Both authors; (V) Data analysis and interpretation: Both authors; (VI) Manuscript writing: Both \\ authors; (VII) Final approval of manuscript: Both authors. \\ Correspondence to: Prof. Federico Canavese, MD, PhD. Lille University Center, Jeanne de Flandre Hospital, Department of Pediatric Orthopedic \\ Surgery, Rue Eugène Avinée, 59000 Lille France. Email: canavese_federico@yahoo.fr.
}

\begin{abstract}
Clinical examination of the newborn's foot is a complex exercise that requires a lot of sensitivity, practice and deep understanding of normal and pathological anatomy, and the clinical assessment of a child with congenital talipes equinovarus, or congenital clubfoot, must be complete and it should not be limited to a simple orthopedic evaluation of the foot; the search for a cause is a pressing concern. This narrative review article aims to provide the key information about clinical examination of children with congenital clubfoot; classification systems are also described. Clinical examination of children with congenital clubfoot is essential. In particular, it is important to evaluate the mental age of the child (developmental milestones), to rule out the presence of a spinal dysraphism, to eliminate a mild form of neurological disease (congenital myopathy or arthrogryposis), as well as to carefully examine the face and hands of the patient. The examination of the foot and the classification of the clubfoot deformity complete the clinical evaluation. In the end, the pediatric orthopedic surgeon must not underestimate any clinical signs, and must act as a pediatrician. This narrative review summarizes the key points in taking a history and performing a comprehensive clinical examination for patients with congenital clubfoot; the review also briefly describes the normal foot anatomy and growth as to give the reader the opportunity to better understand the morphological and functional modifications secondary to congenital clubfoot.
\end{abstract}

Keywords: Clubfoot; clinical examination; classification; Dimeglio; Pirani

Submitted Nov 17, 2020. Accepted for publication Jan 15, 2021.

doi: $10.21037 /$ atm-20-7524

View this article at: http://dx.doi.org/10.21037/atm-20-7524

\section{Introduction}

Clinical examination of the newborn's foot is a complex exercise that requires a lot of sensitivity, practice, and deep understanding of normal and pathological anatomy. At birth, only one third (35\%) of the foot is already ossified (1). At this stage bones are still cartilaginous, soft and malleable, whereas fibrous structures are more resistant and stiffer. Within the spectrum of all possible Congenital Talipes EquinoVarus (CTVE) or clubfoot conditions, there are different degrees of involvement and severity, ranging from the stiffest to the softest foot (1-9).

This narrative review summarizes the key points in

^ ORCID: Federico Canavese, 0000-0002-6114-5372; Alain Dimeglio, 0000-0003-1371-1189. 
taking a history and performing a comprehensive clinical examination for patients with CTVE; the review also briefly describes the normal foot anatomy and growth as to give the reader the opportunity to better understand the morphological and functional modifications secondary to CTVE.

Within the spectrum of all possible CVTE conditions, there are different degrees of involvement, from the stiffest to the softest foot. This review also highlights classifications are essential to score clubfoot at birth (from the mildest to the most severe), to rapidly identify those to be treated, and to assess the impact of treatment objectively.

This narrative review should be intended as a guide for practitioners dealing with children with CTVE. We present the following article in accordance with the Narrative Review reporting checklist (available at http://dx.doi. org/10.21037/atm-20-7524).

\section{Search strategy}

We extensively search on commonly used biomedical databases, including PubMed, Embase, MEDLINE (OVID) and Web of Science from the inception of relevant database to November 2020. We combined subject words and keywords using Boolean operators to search with no limitations on year of publication. The following search terms were used: "clinical assessment", "classification", "foot", "children" and "clubfoot". We used limits of "English language" and "all children 0-5 years". According to the search criteria, two researchers (FC and AD) independently screened and extracted the data. Disagreements were resolved by consensus among the authors. All articles were level IV case series and expert opinion and, hence no systematic assessment of study quality was performed.

\section{Normal foot}

At birth the foot measures between 7 and $10 \mathrm{~cm}$, the longitudinal arch is often masked by fat pads and the sole is triangular in shape, wider anteriorly and narrow in the heel; in particular, the average foot width is about one half its length and becomes about one third of its length during adulthood. As a rule of thumb, if the index and middle finger can be placed along the borders of the foot and remain in contact with its medial and lateral side, the foot can be considered to have normal morphology (10).

The feet of the newborn are very flexible and the range of movement of the different joints is relatively wide. In particular, (I) ankle dorsiflexion and plantarflexion can exceed $55^{\circ}$ and $45^{\circ}$, respectively; (II) the subtalar joint has a broad range of movement $\left(35^{\circ}\right)$, from $20^{\circ}$ of inversion to $15^{\circ}$ of eversion; (III) the mobility of the toes is significant, in particular at the level of the first metatarsophalangeal joint $\left(90^{\circ}\right.$ of dorsiflexion and $90^{\circ}$ of plantarflexion); (IV) forefoot adduction is slightly greater than abduction; (V) the first and the second metatarsals are almost equal in length and are longer than the remaining three that tend to adduct $15^{\circ}$ to $35^{\circ}$.

\section{The anatomy of normal dorsiflexion}

The understanding of the mechanisms that regulate normal dorsiflexion at the ankle joint is extremely important to appreciate the abnormalities of the CTVE deformity. As the foot moves from equino-varus to calcaneo-valgus, dorsiflexion occurs both at the level of the ankle and of the subtalar joint. At the level of the ankle, the body of the talus lies posteriorly and also rotates so that the head of the talus moves laterally in the mortice. However, due to the morphology of the talus, the foot can reach a plantigrade position only if the foot further externally rotates at the level of the subtalar joint; in particular, the central axis of this movement is the interosseous talo-calcaneal ligament that plays the role of "central pivot" similar to the cruciate ligaments of the knee, as pointed out by several authors (1,11-13). It may be estimated that for every $10^{\circ}$ of dorsiflexion from the position of equino-varus, there is a $10^{\circ}$ of external rotation of the tibia; the lateral malleolus remains forward as the foot is progressively dorsiflexed.

\section{Postural clubfoot}

At birth, it is important to differentiate between postural and rigid CTEV in which the deformity is stiff and the range of movement is limited. The postural clubfoot shows inversion of the hind foot, adduction and inversion of the forefoot and the entire foot is plantar flexed at the level of the ankle. Usually there are neither abnormal skin creases nor calf atrophy. The deformity is supple and on passive manipulations it is fully correctible.

\section{Congenital clubfoot}

The clinical assessment of a child with CTVE must be complete and it should not be limited to a simple orthopedic evaluation of the foot. In particular, before 
starting to examine the foot, it is important to check if the child has developed normally (developmental milestones), to rule out a mild form of neurological disease (congenital myopathy or arthrogryposis), to eliminate a spinal dysraphism, as well as to carefully examine the face and hands of the patient. In the end, the pediatric orthopedic surgeon must not underestimate any clinical signs, and must act as a pediatrician. A neonatal ultrasound assessment is recommended to check the medullary axis, the state of the brain and of the heart as certain affections can be revealed secondarily.

Feet must be manipulated gently and gradually and during clinical examination babies must be relaxed; palpation is an essential step since there is no substitute for the tactile feeling of an expert's hand; for example, the stiffness of the hind foot could suggest a neonatal synostosis, not visible on plain radiographs.

In newborns with congenital clubfoot, the foot is generally rigid and ankle range of motion is limited. Depending on the severity of the clubfoot, the clinical presentation may vary between relatively soft and reducible, and stiff and irreducible feet. It must be remembered that the difficulty with which a clubfoot corrects is not always directly dependent upon the degree of deformity. It is more related to the rigidity. Therefore, in order to evaluate the severity of the deformity objectively, as well as to assess the outcome of treatment, a classification system is necessary even though all classifications are necessarily arbitrary (4).

When looking at a CTEV, five basic steps must be carefully followed by the examiner:

(I) To palpate the heel in order to evaluate whether the calcaneus is present or not (empty heel);

(II) To assess whether the lateral border of the foot it is straight or convex (convex lateral border);

(III) To evaluate the reducibility of the foot on all planes: (i) rotation of the calcaneo-tarsal complex and forefoot adduction on the horizontal plane; (ii) ankle dorsiflexion (equinus) on the sagittal plane; and (iii) hind foot varus on the frontal plane.

(IV) To test the tonicity of the muscles. Muscle testing for motor strength is difficult to perform in a newborn. However, because ruling out neuromuscular non-idiopathic clubfoot is important, a muscle test should be performed even though it is difficult to be performed; he quality and the activity of the muscles are decisive factors for deformity progression.

(V) To test the other joints. Hips, knees, elbows, shoulders have to be examined to rule out subluxation, dislocation or deformity.

In order correctly evaluate the deformities of the hind foot and forefoot, it is of outmost importance to correctly orientate the tibia, with respect to the position of the tibial tubercule and the medial and lateral malleolus. Having oriented the tibia, the position of the head of the talus and the alignment of the calcaneus and its orientation, the position of the forefoot in relationship to the hind foot can be assessed and evaluated. It is important to remember that recurvatum of the knee can mask equinus while external rotation of the leg can mask forefoot adduction.

In patients with CTVE, the forefoot and midfoot are inverted and adducted with the navicular bone tethered to the medial malleolus. The foot appears convex on the lateral side and concave on the medial one (medial crease); the big toe appears shortened because of the adduction and inversion deformity of the medial column of the foot. The hindfoot is in varus and heel is drawn up by a retracted Achille's tendon (equinus) and a deep crease is usually present on the posterior aspect of the ankle joint (posterior crease). The skin on the lateral aspect of the foot in front of the lateral malleolus is thin, with a prominent body of the talus under it. Moderate to severe calf atrophy is generally present although when significant is a pejorative criterion.

Dorsalis pedis and tibial artery pulses are usually present but vascular dysgenesis is possible, so it is important to assess circulation of the foot and ankle.

At the end of this detailed clinical assessment, the examiner should be able to identify and differentiate the following key clinical findings:

* Short and fat (chubby) foot versus long and thin foot;

* Reducibility of the foot $<50 \%$ versus $>50 \%$;

* Lack of dorsal flexion and severity of the equinus $(>20 \%)$;

* Absence versus presence of creases (posterior, medial and/or plantar);

* Severity of the atrophy of the calf muscles;

* Reactivity of the peroneal muscles.

\section{Clubfoot classification systems}

Within the spectrum of all possible CVTE conditions, there are different degrees of involvement, from the stiffest to the softest foot. Although arbitrary, classifications are essential to score clubfoot at birth (from the mildest to the most severe), to rapidly identify those to be treated, and 
to assess the impact of treatment objectively. In particular, classification systems must be simple, easy to teach, and consistently repeatable by different examiners.

Several classification systems have been developed during the past five decades or so. However, the most commonly used clinical classification systems are those described by Ponseti and Smoley, Manes et al., Harrold and Walker, Catterall, Goldner and Fitch, Dimeglio et al. and Pirani; the International Clubfoot Study Group (ICSG) classification, introduced by Bensahel in 2003, and the Carroll's grading system evaluate the outcome of treatment (13-18).

The most frequently used clinical systems to evaluate clubfoot severity at birth are the Dimeglio et al. classification system and the Pirani score.

Several studies have evaluated the interobserver and intraobserver reliability of different classification systems; Wainwright et al. studied the reliability of four clinical classification systems-those described by Catterall, Dimeglio et al., Harrold and Walker, and Ponseti and Smoley, and found the system of Dimeglio et al., the most reliable of the four (5). In addition, Flynn et al. (6) and Celebi et al. (7) have shown that after an initial learning curve Dimeglio et al.'s grading system, Pirani's score and ICSG classification system have good interobserver and intraobserver reliability.

\section{Dimeglio et al. classification system [1995]}

According to Dimeglio et al., at birth CTVE can be divided into four categories, according to the severity of the deformity $(4,19,20)$. In particular, in order to obtain the final score (from 0 to 20), each of the following parameters is scored from 1 (completely reducible) to 4 (non-reducible) (4):

(I) Forefoot adduction (up to 4 points): one point is given if forefoot adduction can be fully corrected and it reaches $+20^{\circ}$ of abduction, two if neutral position $\left(0^{\circ}\right)$ can be achieved, three points if forefoot adduction cannot be corrected and it stops at $-20^{\circ}$ from neutral position, and four points if forefoot adduction is blocked at around $-45^{\circ}$.

(II) Internal rotation of the calcaneo-tarsal complex (up to 4 points): one point is given if the calcaneo-tarsal complex can be externally rotated up to $+20^{\circ}$, two points if it can reach the neutral position $\left(0^{\circ}\right)$, three points if the calcaneo-tarsal complex cannot be externally rotated and it stops at $-20^{\circ}$ from neutral position, and four points if internal rotation does not exceed $-45^{\circ}$.
(III) Varus of the hind foot (up to 4 points): one point is given if hind foot can reach $+20^{\circ}$ of valgus, two points if neutral position ca be reached, three points if the hind foot varus cannot be fully corrected and $-20^{\circ}$ of varus remains, and four points if hindfoot varus cannot be corrected above $-45^{\circ}$;

(IV) Equinus (up to 4 points): one point is attributed if ankle dorsal flexion reaches $+20^{\circ}$, two points if neutral position $\left(0^{\circ}\right)$ can be reached, three points if ankle dorsal flexion is around $-20^{\circ}$, and four points if equinus cannot be corrected above $-45^{\circ}$;

All these parameters must be assessed without forcing the foot, and a small goniometer can be used to measure all angles precisely, before and after the reduction maneuver.

Four pejorative points can then be added to the score of the four main parameters as to obtain a total score out of 20 points maximum: (I) one point is added if a medial crease is present; (II) one point is added if a posterior crease is present; (III) one point is added in the foot has cavus; and (IV) one point is added if the infant has hypertonia, muscle weakness or short chubby foot.

The Diméglio et al. classification system allows the treating surgeon to identify four categories of CTVE, and to predict the outcome (4):

(I) Score $\leq 5 / 20$ points: soft-soft or postural feet. These feet that can be completely reduced. Any treatment can correct the deformity and it is exceptional that these feet become stiff.

(II) Score 6-10 points: soft-stiff or moderate feet. These feet are partially resistant, and can be reduced ( $>50 \%$ of reduction). Orthopedic treatment is generally effective and extensive surgery is avoided in more than $90 \%$ of cases.

(III) Score 11-15 points: stiff-soft or severe feet. These feet can be partially reduced ( $<50 \%$ of reduction) and are generally resistant. Orthopedic treatment is effective in about $50 \%$ of cases and surgery is performed in cases not responding to conservative treatment.

(IV) Score $\geq 16$ points: stiff-stiff feet. These feet are generally stiff and reduction, if any, is extremely limited. About $30 \%$ of these feet are not idiopathic and extensive surgery is needed in about $65 \%$ of cases.

The Diméglio et al. classification system is simple, reproducible and reliable. It permits to assess the effectiveness of the orthopaedic treatment day by day during the first 6 months of life, and it allows for reliable 
comparisons between study populations that use various treatment techniques.

\section{Pirani score [1995]}

The Pirani Score is a simple and reliable system to determine severity and treatment progress in children with CTVE. The Pirani score works by assessing six clinical signs of contracture, 0 (no deformity), 0.5 (moderate deformity) or 1 (severe deformity). In particular, three signs are in the midfoot and three in the hind foot.

The mid foot signs are: medial crease (several fine creases are $0 ; 2$ to 3 mild creases are 0.5 ; one deep crease is 1 ), curved lateral border (straight is 0 ; deviation at the level of the metatarsals is 0.5 ; deviation at the calcaneo-cuboid joint is 1) and lateral head of talus (completely mobile is 0 ; partially mobile is 0.5 ; fixed is 1 ).

The hind foot signs are: posterior crease (several fine creases are $0 ; 2$ to 3 mild creases are 0.5 ; one deep crease is 1), empty heel (calcaneus easily palpable is 0 ; palpable but deep is 0.5 ; not palpable is 1 ) and rigid equinus (dorsiflexion possible is 0 ; dorsiflexion reaches neutral position is 0.5 ; rigid equinus is 1 ).

The Pirani score has been shown to be easy to use, reliable to determine severity and monitor progress in the treatment of clubfoot, and with good interobserver reliability. In addition, Dyer et al. (14) and Mejabi et al. (15) reported there is significant positive correlation between the initial Pirani score and number of casts required to correct the clubfoot deformity. In addition, Mejabi et al. also showed a correlation between the Pirani score and the need for Achilles tenotomy exists (15).

\section{Goldner and Fitch classification [1994]}

Goldner and Fitch classification system of CTEV deformity provides an index of severity that can be used as a guide to treatment. The system includes eight clinical and two radiographic parameters.

Clinical items are: (I) skin, ligaments, creases, elasticity; (II) calf size, ease of cast application; (III) muscles activity; (IV) position of the head of the talus; (V) tibial-navicular interval; (VI) foot alignment with ankle joint; (VII) equinus; (VIII) cavus.

Radiographic items are: (I) evaluation of hind foot (position of the talus and of the calcaneus as well as their relationship; (II) abduction and adduction, spurious correction of forefoot.
Each parameter is rated as absent ( 0 points), mild (1, 2 or 3 points according to the severity), moderate (2, 4 or 6 points) e or severe (3, 6 or 9 points); the total score gives the severity of the CTVE deformity.

\section{Catterall classification [1991]}

The Catterall's system for the classification of CVTE assess nine clinical signs of contracture to identify four patterns of deformity: resolving pattern, tendon contracture, joint contracture and false correction. In particular, five signs are in the hind foot and four in the hind foot.

The hind foot signs are: lateral malleolus (mobile or posterior), equinus (yes or no), medial crease (yes or no), posterior crease (yes or no) and anterior crease (yes or no).

The forefoot signs are lateral border (straight or curved), mobility (yes or no), foot cavus (yes or no) and supination (yes or no).

\section{Harrold and Walker classification [1983]}

The system of Harrold and Walker for the classification of CVTE is based on the ability to correct the deformity and identifies three types of deformity: mild, moderate and severe.

According to Harrold and Walker mild clubfoot deformity (grade 1) can be corrected at or beyond neutral position, moderate clubfoot deformity (grade 2) has less than $20^{\circ}$ of residual varus and equinus, and severe deformity (grade 3 ) has more than $20^{\circ}$ of residual varus and equinus.

\section{Manes, Costa and Innao classification system [1975]}

The Manes, Costa and Innao classification system assesses the severity of the CVTE deformity exclusively on the sagittal plane and it identifies three degrees of severity: grade I, the deformity is mild and completely reducible; grade II, the deformity is moderate and partially reducible; grade III, the deformity is severe and not reducible (stiff) (16).

\section{Ponseti and Smoley classification [1963]}

The classification system of Ponseti and Smoley is based on four clinical parameters: ankle dorsiflexion (absent, $0^{\circ}$ to $10^{\circ}$ or $\left.>10^{\circ}\right)$, heel varus $\left(0^{\circ}\right.$ to $10^{\circ}, 10^{\circ}$ to $20^{\circ}$ or rigid, $\left.>20^{\circ}\right)$, forefoot adduction $\left(0^{\circ}\right.$ to $10^{\circ}, 10^{\circ}$ to $20^{\circ}$ or rigid, $\left.>20^{\circ}\right)$, and tibial torsion (absent, moderate and severe). Feet can be classified on the basis of these measurements as either good, 
acceptable or poor.

According to the original article of Ponseti and Smoley, acceptable and poor cutoffs for each parameter were as follow: dorsiflexion of the ankle of more than 10 degrees with the knee in extension and complete correction of heel varus, forefoot adduction and tibial torsion; in particular, good outcome should be expected in more than $70 \%$ of cases (19).

\section{Clubfoot evaluation during growth}

CTVE is a congenital (in utero) deformity. Although treatment can successfully correct the deformity, the affected foot will never be completely normal as a CTVE remains a CTVE throughout life. In particular, the affected foot is shorter, the calf is smaller and range of monition is reduced compared to the contralateral one; while CTVE is usually described as a defect of the foot, the musculature between the knee and the ankle is affected to some degree, and the size difference between affected and not affected side persists for the whole life. This is a crucial and realistic point that has to be discussed with the family, before any treatment is started.

A regular and objective clinical assessment is necessary to assess the evolution of the correction obtained with the initial treatment; spacing appointments every one to two years should therefore be avoided (20).

The clinical assessment of the foot during growth should evaluate the overall shape of the foot (straight or 'bean shaped'), the presence of any deformity at the level of the hind foot (varus or valgus) and forefoot (adduction), the mobility of the subtalar joint, the plantar and dorsal flexion of the ankle, the atrophy of the calf and the anatomical axis of the lower limb.

The functional assessment should evaluate the capacity of the patient to toe and heel walk, to walk down the stairs, to stand on one leg, to jump a rope, to walk on uneven terrain, and the type and severity of gait abnormality, if any. It is important to rule out the presence of a recurvatum knee which can mask a residual equinus, a weakness of the triceps surae which is always detrimental, and a weakness of the flexors of the toes.

The radiographic assessment plays an essential role in the evaluation of CTVE. In particular, the divergence between the talus and the calcaneus on antero-posterior and lateral view should be evaluated as well as the morphology of the bones, particularly a crushing of the head of talus (flattening), or a subluxation of the navicular bone which is always a pejorative factor. The ossification of the navicular bone, around the age of 5 years, allows a more precise evaluation of the foot. The evaluation should be repeated at the age of 10 years. This comprehensive clinical and radiographic assessment performed at age 5 and 10 years help to objectively evaluate the outcome (and change opinion on some good results); in fact, the limited mobility of these feet can be striking: even if the plantar and dorsal flexion is correct, the limitations to prono-supination are much more frequent than is commonly believed. A clubfoot is always highly disabling; only $50 \%$ of children are able to correctly walk on tiptoes, especially after extensive surgery.

\section{Gait analysis and plantar pressure measurements}

Gait analysis can provide accurate measurements of foot kinematics and kinetics during the gait cycle of patients with CTVE $(21,22)$ while plantar pressure measurements can provide objective data foot contact and foot loading during the roll over process $(23,24)$.

Several gait analysis studies have evaluated children with successfully treated CTVE as well as children with recurrent deformity; in particular, gait analysis can assess intoeing gait, internal tibial torsion, knee hyperextension, and drop foot during gait and it can objectively evaluate the effect of surgery on temporal, spatial, kinematic and kinetic parameters of the foot and ankle $(21,22)$.

Plantar pressure measurements provide detailed information about the whole foot contact and loading in various foot regions during the roll over process, as well as the metatarsal landing sequence. In particular, pressure measurements analyze the force across a defined surface of the foot and can provide several parameters of interest such as peak pressure, contact area, contact time, and maximum force, and can be recorded for barefoot or inshoe patterns $(23,24)$.

\section{Carroll system for evaluating the outcome of CTVE treatment}

The system developed by Norris Carroll is based on a 20 points grading scale. The system takes into account 20 parameters, ranging from calf circumference to the ability of patients to walk on heels or toes. The ability to do a given activity (i.e., walk on toes) or anatomical parameters close to normal (i.e., less than $0.5 \mathrm{~cm}$ leg length discrepancy between clubfoot and contralateral side) are rated 1 point while abnormal parameters/inability to perform adequately 
a given activity are scored 0 point. A perfectly normal foot would score 20 points. A foot that scores 5 points or less may require further treatment, including surgery $(17,18,21)$.

\section{Conclusions}

In conclusion, the clinical examination of the CTVE deformity and its evaluation are not always an easy task. The following points should be remembered:

* A meticulous and repetitive clinical examination is essential before any attempt to classify a CTVE deformity;

* Classifications help to predict the outcome of the conservative treatment, to monitor the evolution of treatment, and to estimate the surgical risk;

* Regardless of the classification system used, it is essential to distinguish between postural feet, moderate, severe or very sever feet.

\section{Acknowledgments}

Funding: None.

\section{Footnote}

Provenance and Peer Review: This article was commissioned by the editorial office, Annals of Translational Medicine for the series "Clubfoot". The article has undergone external peer review.

Reporting Checklist: The authors have completed the Narrative Review reporting checklist. Available at http:// dx.doi.org/10.21037/atm-20-7524

Peer Review File: Available at http://dx.doi.org/10.21037/ atm-20-7524

Conflicts of Interest: Both authors have completed the ICMJE uniform disclosure form (available at http://dx.doi. org/10.21037/atm-20-7524). The series "Clubfoot" was commissioned by the editorial office without any funding or sponsorship. FC and AD served as the unpaid Guest Editors of the series. FC serves as an unpaid editorial board member of Annals of Translational Medicine from Nov 2020 to Oct 2022. The authors have no other conflicts of interest to declare.

Ethical Statement: The authors are accountable for all aspects of the work in ensuring that questions related to the accuracy or integrity of any part of the work are appropriately investigated and resolved.

Open Access Statement: This is an Open Access article distributed in accordance with the Creative Commons Attribution-NonCommercial-NoDerivs 4.0 International License (CC BY-NC-ND 4.0), which permits the noncommercial replication and distribution of the article with the strict proviso that no changes or edits are made and the original work is properly cited (including links to both the formal publication through the relevant DOI and the license). See: https://creativecommons.org/licenses/by-nc-nd/4.0/.

\section{References}

1. Dimeglio A. Le pied bot. Sauramps Médical diffusion Vigot, Montpellier, France 1985.

2. Charles YP, Canavese F, Dimeglio A. Frühfunktionnelle Behandlung beim angeborenen Klumpfuß. Der Orthopäde 2006;35:668-74.

3. Dimeglio A, Canavese F. Pie zambo: revision de los tratamientos actuals. Rev Ortop Traumatol 2006;50:156-63.

4. Diméglio A, Bensahel H, Souchet $\mathrm{P}$, et al. Classification of clubfoot. J Pediatr Orthop B 1995;4:129-36.

5. Wainwright AM, Auld T, Benson MK, et al. The classification of congenital talipes equinovarus. J Bone Joint Surg Br 2002;84:1020-4.

6. Flynn JM, Donohoe M, Mackenzie WG. An independent assessment of two clubfoot classification systems. J Pediatr Orthop 1998;18:323-7.

7. Celebi L, Muratli HH, Aksahin E, et al. Evaluation of treated clubfoot: Assessment of interobserver and intraobserver reliability. J Pediatr Orthop B 2006;15:34-6.

8. Cooper DM, Dietz FR. Treatment of congenital idiopathic clubfoot. A thirty-year follow-up note. J Bone Joint Surg Am 1995;77:1477-89.

9. Morcuende JA, Dolan LA, Dietz FR, et al. Radical reduction in the rate of extensive corrective surgery for clubfoot using the Ponseti method. Pediatrics 2004; 113 : 376-80.

10. Bernhardt DB. Prenatal and Postnatal Growth and Development of the Foot and Ankle. Phys Ther 1988;68:1831-9.

11. Catterall A. Ex umbris eruditio. J Bone Joint Surgery Br 1968;50:455.

12. Scott WA, Hosking SW, Catterall A. Club foot. 


\section{Page 8 of 8}

Observations on the surgical anatomy of dorsiflexion. J

Bone Joint Surg Br 1984;66:71-6.

13. Barnett $\mathrm{CH}$, Napier JR. The axis of the rotation at the ankle joint in man, its influence upon the form of the talus and mobility of the fibula. J Anat 1952;86:1.

14. Dyer PJ, Davis N. The role of the Pirani scoring system in the management of club foot by the Ponseti method. J Bone Joint Surg Br 2006;88:1082-4.

15. Mejabi JO, Esan O, Adegbehingbe OO, et al. The Pirani Scoring System is Effective in Assessing Severity and Monitoring Treatment of Clubfeet in Children. Br J Med Med Res 2016;17:1-9.

16. Manes E, Costa CM, Innao V. Treatment of congenital clubfoot during the first year of life. Chir Organi Mov 1975;62:301-14.

17. Tarraf YN, Carroll N. Analysis of the Components of Residual Deformity in Clubfeet Presenting for Reoperation. J Pediatr Orthop 1992;12:207-16.

18. Dimeglio A. Le pied bot varus equin : regard sur le monde actuel. Acta Ortop Belgica 1998;64:80-2.

Cite this article as: Canavese F, Dimeglio A. Clinical examination and classification systems of congenital clubfoot: a narrative review. Ann Transl Med 2021;9(13):1097. doi: 10.21037/atm-20-7524

\section{Canavese and Dimeglio. Examination and classification of clubfoot}

19. Ponseti IV, Smoley EN. Congenital Club Foot: The Results of Treatment. J Bone Joint Surg Am 1963;45:261-344.

20. Canavese F, Mansour M, Moreau-Pernet G, et al. The hybrid method for the treatment of congenital talipes equinovarus: preliminary results on 92 consecutive feet. J Pediatr Orthop B 2017;26:197-203.

21. Asperheim MS, Moore C, Carroll NC, et al. Evaluation of residual clubfoot deformities using gait analysis. J Pediatr Orthop B 1995;4:49-54.

22. Jeans KA, Erdman AL, Jo CH, et al. A Longitudinal Review of Gait Following Treatment for Idiopathic Clubfoot: Gait Analysis at 2 and 5 Years of Age. J Pediatr Orthop 2016;36:565-71.

23. Sinclair MF, Bosh K, Rosenbaum D, et al. Pedobarographic Analysis Following Ponseti Treatment for Congenital Clubfoot. Clin Orthop Relat Res 2009;467:1223-30.

24. Favre P, Exner GU, Drerup B, et al. The contralateral foot in children with unilateral clubfoot: a study of pressures and forces involved in gait. J Pediatr Orthop 2007;27:54-9. 